\title{
Inhibition of PKM $\zeta$ in Nucleus Accumbens Core Abolishes Long-Term Drug Reward Memory
}

\author{
Yan-qin Li, ${ }^{1}$ Yan-xue Xue, ${ }^{1}$ Ying-ying He, ${ }^{1}$ Fang-qiong $\mathrm{Li},{ }^{1}$ Li-fen Xue, ${ }^{1}$ Chun-mei Xu, ${ }^{1}$ Todd Charlton Sacktor, ${ }^{2,3}$ \\ Yavin Shaham, ${ }^{4}$ and $\mathrm{Lin} \mathrm{Lu}^{1}$ \\ ${ }^{1}$ National Institute on Drug Dependence, Peking University, Beijing 100191, China, Departments of ${ }^{2}$ Physiology and Pharmacology and ${ }^{3}$ Neurology, SUNY \\ Downstate Medical Center, New York 11203, ${ }^{4}$ Intramural Research Program, National Institute on Drug Abuse, National Institutes of Health, Baltimore MD \\ 21224
}

During abstinence, memories of drug-associated cues persist for many months, and exposure to these cues often provokes relapse to drug use. The mechanisms underlying the maintenance of these memories are unknown. A constitutively active atypical protein kinase $C$ ( $\mathrm{PKC})$ isozyme, protein kinase $\mathrm{M} \zeta(\mathrm{PKM} \zeta)$, is required for maintenance of spatial memory, conditioned taste aversion, and other memory forms. We used conditioned place preference (CPP) and conditioned place aversion (CPA) procedures to study the role of nucleus accumbens $\mathrm{PKM} \zeta$ in the maintenance of drug reward and aversion memories in rats. Morphine CPP training (10 mg/kg, 4 pairings) increased $\mathrm{PKM} \zeta$ levels in accumbens core but not shell. Injections of the PKM $\zeta$ inhibitor $\zeta$ inhibitory peptide (ZIP) into accumbens core but not shell after CPP training blocked morphine CPP expression for up to $14 \mathrm{~d}$ after injections. This effect was mimicked by the PKC inhibitor chelerythrine, which inhibits $\mathrm{PKM} \zeta$, but not by the conventional and novel PKC inhibitor staurosporine, which does not effectively inhibit PKM $\zeta$. ZIP injections into accumbens core after training also blocked the expression of cocaine (10 mg/kg) and high-fat food CPP but had no effect on CPA induced by naloxone-precipitated morphine withdrawal. Accumbens core injections of Tat-GluR2 $2_{3 Y}$, which inhibits GluR2-dependent AMPA receptor endocytosis, prevented the impairment in morphine CPP induced by local ZIP injections, indicating that the persistent effect of PKM $\zeta$ is on GluR2-containing AMPA receptors. Results indicate that PKM $\zeta$ activity in accumbens core is a critical cellular substrate for the maintenance of memories of relapse-provoking reward cues during prolonged abstinence periods.

\section{Introduction}

Relapse to drug use during abstinence is a major clinical problem (Hunt et al., 1971). Seminal studies by Wikler (1973) and O'Brien et al. (1986) indicate that exposure to craving-provoking environmental cues previously associated with drug use and effects is a major cause of drug relapse. Based on these studies, they concluded that Pavlovian conditioning processes play a major role in drug addiction and that drug-associated memories persist for months and years after cessation of drug use. In laboratory rats, cues previously associated with drug intake also provoke drug seeking after prolonged abstinence (Grimm et al., 2001; Ciccocioppo et al., 2004; Di Ciano and Everitt, 2004). However, while many investigators have explored the neuropharmacological

\footnotetext{
Received Nov. 8, 2010; revised Jan. 26, 2011; accepted Feb. 12, 2011.

This work was supported in part by the National Basic Research Program of China (No. 2009CB522004), the Natural Science Foundation of China (№. 30725016), Natural Science Foundation of Beijing Municipality (No. 09G0762), the Intramural Research Program of the National Institute on Drug Abuse [National Institutes of Health (NIH), Department of Health and Human Services], and National Institutes of Health Grants MH057068 and MH53576 (T.C.S.). We thank Dr. Emily Wentzell, Anna Stern, and Dr. David Epstein for helpful comments.

The authors declare that they do not have any conflicts of interest (financial or otherwise) related to the data presented in this manuscript.

Correspondence should be addressed to Prof. Lin Lu, National Institute on Drug Dependence, Peking University, 38, Xue Yuan Road, Beijing 100191, China. E-mail: linlu@bjmu.edu.cn.

Y.-q. Li's present address: Department of Pharmacology and Chemical Biology, University of Pittsburgh, Pittsburgh, PA 15261.

DOI:10.1523/JNEUROSCI.5884-10.2011

Copyright $\odot 2011$ the authors $\quad 0270-6474 / 11 / 315436-11 \$ 15.00 / 0$
}

bases of conditioned drug effects and consolidation and reconsolidation of their memories (Everitt and Robbins, 2005; Weiss, 2005; Tronson and Taylor, 2007), the mechanisms mediating the persistence of drug cue memories are unknown.

Recent studies indicate that a constitutively active atypical protein kinase $\mathrm{C}(\mathrm{PKC})$ isozyme, protein kinase $\mathrm{M} \zeta(\mathrm{PKM} \zeta)$, is required for maintaining long-term memories of hippocampusdependent spatial memory (Pastalkova et al., 2006), insula-dependent conditioned taste aversion (Shema et al., 2007, 2009), and other forms of basolateral amygdala- and dorsal hippocampus-dependent long-term instrumental and classical conditioned memories (Serrano et al., 2008; Migues et al., 2010). These studies were inspired by early work by Ling et al. (2002), who demonstrated that PKM $\zeta$ is critical for the maintenance of hippocampal long-term potentiation (LTP). In these studies, the main compound used to inhibit PKM $\zeta$ activity has been a selective peptide inhibitor called $\zeta$ inhibitory peptide (ZIP) (Laudanna et al., 1998; Serrano et al., 2008; Sacktor, 2011).

Here, we used a drug conditioned place preference (CPP) procedure to investigate whether long-term memories for contextual cues previously paired with morphine or cocaine injections are mediated by PKM $\zeta$ activity in nucleus accumbens. Accumbens neuronal activity is associated with cue-induced drug craving in humans (Kilts et al., 2001) and mediates cueinduced drug seeking in rats (Everitt and Robbins, 2005; Crombag et al., 2008). CPP is a classical conditioning procedure entailing a training phase in which one environmental context is 
paired with drug injections, while another context is paired with vehicle (e.g., saline) injections (Mucha et al., 1982). During subsequent drug-free CPP tests, rats choose between the drug- and vehicle-paired contexts. Increased preference for the drug-paired context serves as a measure of the drug's rewarding effects $(\mathrm{Mu}-$ cha et al., 1982; Stewart, 1992).

We report that morphine CPP training increased PKM $\zeta$ levels in accumbens core and that local ZIP injections after CPP training blocked morphine CPP expression for up to $14 \mathrm{~d}$. Accumbens core ZIP injections after training also blocked the expression of cocaine and high-fat food CPP but had no effect on conditioned place aversion (CPA) induced by naloxone-precipitated morphine withdrawal. Finally, Migues et al. (2010) showed that PKM $\zeta$ role in memory maintenance involves a reduction in GluR2-dependent AMPA receptor endocytosis. Thus, we injected into accumbens core Tat-GluR2 3 Y , which inhibits GluR2-dependent AMPA receptor endocytosis, and found that it blocked the impairment in morphine CPP induced by local ZIP injections.

\section{Materials and Methods}

\section{Subjects}

Male Sprague Dawley rats (weighing 220-240 g upon arrival) were housed in groups of five in a temperature- $\left(23 \pm 2^{\circ} \mathrm{C}\right)$ and humidity$(50 \pm 5 \%)$ controlled animal facility. The rats were maintained on a $12 \mathrm{~h}$ light/dark cycle with ad libitum access to food and water. The experimental procedures were performed in accordance with the National Institutes of Health Guide for the Care and Use of Laboratory Animals, and were approved by the local Animal Care and Use Committee. Thirty-eight of the four hundred fifty-eight rats were excluded from experiments due to loss of head cup or cannula misplacement. Forty-two rats that showed strong unconditioned side preference ( $>540 \mathrm{~s}$ ) during the drug preconditioning phase were also excluded.

\section{Drugs}

Morphine sulfate (Qinghai Pharmaceutical), cocaine $\mathrm{HCl}$ (Qinghai Pharmaceutical), and naloxone $\mathrm{HCl}$ (Sigma-Aldrich) were dissolved in $0.9 \%$ physiological saline and injected at a volume of $1 \mathrm{ml} / \mathrm{kg}$. Morphine and naloxone were injected subcutaneously, and cocaine was injected intraperitoneally. The PKM $\zeta$ inhibitor ZIP (myr-SIYRRGARRWRKLOH) [Calbiochem, catalog number (Cat No.) 539624], scrambled ZIP (Tocris Bioscience, Cat No. 3215), AP5 (Sigma-Aldrich, Cat No. A8054), Tat-GluR2 ${ }_{3 Y}$ (YGRKKRRQRRRYKEGYNVYG) (Anaspec, Cat No. 64429), and Scrambled Tat GluR2 $2_{3 Y}$ (YGRKKRRQRRRVYKYGGYNE, Anaspec, Cat No. 64428) were dissolved in PBS (the vehicle). Chelerythrine chloride (Alexis, Cat No. ALX-350-008) and staurosporine (Cell Signaling Technology, Cat No. 9953) were dissolved in 50\% DMSO to a final concentration of $60 \mathrm{nmol} / \mu \mathrm{l}$. Control group rats received injections of vehicle.

\section{Surgery}

Rats were anesthetized with sodium pentobarbital $(60 \mathrm{mg} / \mathrm{kg}$, i.p.). Twenty-three gauge guide cannulae (Plastics One) were bilaterally implanted $1 \mathrm{~mm}$ above the nucleus accumbens core and shell. The cannulae were angled toward the midline at $16^{\circ}$ to avoid penetrating the lateral ventricles. The coordinates (Paxinos and Watson, 2005) for the accumbens core were anterior/posterior $+1.5 \mathrm{~mm}$, medial/lateral $\pm 3.8 \mathrm{~mm}$, dorsal/ventral $-6.2 \mathrm{~mm}$; the coordinates for the accumbens shell were anterior/posterior $+1.8 \mathrm{~mm}$, medial/lateral $\pm 3.2 \mathrm{~mm}$, dorsal/ventral $-6.6 \mathrm{~mm}$ (Zangen et al., 2006; Bossert et al., 2007, 2009). The cannulae were anchored to the skull with stainless steel screws and dental cement. A stainless steel blocker was inserted into each cannula to maintain patency and prevent infection. The rats were allowed to recover from surgery for $5-7 \mathrm{~d}$.

\section{Intracranial injections}

ZIP (10 or $30 \mathrm{nmol} / \mathrm{side} / 0.5 \mu \mathrm{l})$, scrambled-ZIP (30 nmol/side), TatGluR2 $2_{3 \mathrm{Y}}(45 \mathrm{pmol} / \mathrm{side})$ and Scrambled Tat GluR2 ${ }_{3 \mathrm{Y}}(45 \mathrm{pmol} / \mathrm{side})$, chelerythrine chloride (30 nmol/side), staurosporine (30 nmol/side),
AP5 $(0.375 \mu \mathrm{g} / \mathrm{side})$, or their vehicles $(0.5 \mu \mathrm{l} /$ side $)$ were injected bilaterally into accumbens core or shell with Hamilton syringes connected to 30 gauge injectors (Plastics One). The doses of the different compounds were based on previous reports (Pastalkova et al., 2006; Shema et al., 2007, 2009; Serrano et al., 2008; Migues et al., 2010). A total volume of 0.5 $\mu \mathrm{l}$ was injected bilaterally over $1 \mathrm{~min}$, and the injector was kept in place for an additional $1 \mathrm{~min}$ to allow for diffusion. At the end of the experiments, the rats were anesthetized with sodium pentobarbital $(100 \mathrm{mg} / \mathrm{kg}$, i.p.) and transcardially perfused. Cannula placements were assessed using Nissl staining with a section thickness of $40 \mu \mathrm{m}$ under light microscopy. Rats with misplaced cannulae were excluded from statistical analysis. The approximate cannula placements in accumbens core and shell are presented in Figure $2 D$.

\section{Drug CPP}

Morphine CPP was performed using an unbiased, counterbalanced protocol (Li et al., 2008, 2010; Wang et al., 2008). The CPP apparatus consisted of five identical three-chamber polyvinyl chloride (PVC) boxes. Two large side chambers $(27.9 \mathrm{~cm}$ long, $21.0 \mathrm{~cm}$ wide, $20.9 \mathrm{~cm}$ high $)$ were separated by a smaller one $(12.1 \mathrm{~cm}$ long, $21.0 \mathrm{~cm}$ wide, $20.9 \mathrm{~cm}$ high with a smooth PVC floor). The two larger chambers differed in their floor texture (bar or grid, respectively), and provided distinct contexts that were paired with morphine, cocaine, high-fat-food, or saline injections. Three distinct chambers were separated by manual guillotine doors.

Baseline preference was assessed by placing the rats in the center compartment of the CPP apparatus and allowing ad libitum access to all compartments for $15 \mathrm{~min}$. On subsequent conditioning days, the rats were trained for 8 consecutive days with alternating injections of morphine $(10 \mathrm{mg} / \mathrm{kg}$, s.c.) or saline ( $1 \mathrm{ml} / \mathrm{kg}$, s.c. $)$ in the designated compartments. After each injection, the rats were confined to the corresponding conditioning chambers for $45 \mathrm{~min}$ and then returned to their home cages. Tests for the expression of drug CPP in a drug-free state (15 min duration) were performed at different days after training. The procedure during testing was the same as during the initial baseline preference assessment. The CPP score was defined as the time (in seconds) spent in the reward-paired chamber minus the time spent in the saline-paired chamber during CPP testing. The training and testing procedure for cocaine CPP was identical, except that cocaine $(10 \mathrm{mg} / \mathrm{kg}$, i.p. $)$ was injected instead of morphine.

\section{High-fat food CPP}

Before the start of the experiment, the rats received a small portion ( $1 \mathrm{~g})$ of the high-fat food (Research Diets) (Zhang et al., 1998) for $5 \mathrm{~d}$ in their home cage, to minimize food neophobia. The CPP procedure for highfat food is based on the previous work of Figlewicz et al. (2004) and includes three phases, similar to those used in the drug CPP procedures.

Baseline preference was assessed by placing the rats in the center compartment of the CPP apparatus and allowing ad libitum access to all compartments for $15 \mathrm{~min}$. The $8 \mathrm{~d}$ training phase included four $2 \mathrm{~d}$ cycles in which rats received a $5 \mathrm{~g}$ aliquot of the high-fat food [ $\sim 30 \mathrm{kcal}(126 \mathrm{~kJ})$ per aliquot] in one chamber on one day and no food in the other chamber on the other day. The duration of the daily training sessions was $45 \mathrm{~min}$. The 15 min tests for the expression of CPP were conducted in the absence of the high-fat food at different days after CPP training and ZIP injections. During testing, the rats were allowed to freely explore the chambers. The CPP score is defined as the time (in seconds) spent in the high-fat food-paired chamber minus the time spent in the no-foodpaired chamber.

\section{Naloxone-precipitated morphine withdrawal CPA}

The CPA procedure for naloxone-precipitated opiate withdrawal is based on previous work of Azar et al. (2003). The procedure includes three phases similar to morphine CPP described above: baseline preference test, CPA training, and test for the CPA expression.

Baseline preference was assessed by placing the rats in the center compartment of the CPP apparatus and allowing ad libitum access to all compartments for $15 \mathrm{~min}$. The CPA training included four $2 \mathrm{~d}$ cycles. In each cycle, naloxone-precipitated opiate withdrawal was paired with one of the chambers for $45 \mathrm{~min}$ on one day, and "no withdrawal" was paired with the other chamber on the other day. Naloxone-precipitated with- 
drawal was induced by injecting morphine $(5 \mathrm{mg} / \mathrm{kg}$, s.c.) followed $4 \mathrm{~h}$ later by naloxone $(0.3 \mathrm{mg} / \mathrm{kg}$, s.c.); the rats were confined to the chamber immediately after the naloxone injection. The "no withdrawal" condition included two injections of saline $(1 \mathrm{ml} / \mathrm{kg}) 4 \mathrm{~h}$ apart; the rats were confined to the "no withdrawal" chamber for 45 min immediately after the second injection. The 15 min tests for the expression of naloxoneprecipitated opiate withdrawal CPA were conducted in a drug-free state at different time points following CPA training and ZIP injections. During testing, the rats were allowed to freely explore the apparatus' chambers. The CPA score is defined as the time (in seconds) spent in the naloxone-precipitated-withdrawal-paired chamber minus the time spent in the no-withdrawal-paired chamber.

\section{Tissue sample preparation}

In experiments in which PKM $\zeta$ levels were determined by Western blots, rats were rapidly decapitated without anesthesia $1 \mathrm{~d}$ after the $15 \mathrm{~min}$ CPP tests. After decapitation, the brains were quickly extracted and frozen in $-60^{\circ} \mathrm{C} \mathrm{N}$-hexane. The brains were then transferred to a $-80^{\circ} \mathrm{C}$ freezer. We used a freezing cryostat $\left(-20^{\circ} \mathrm{C}\right)$ to make $1-\mathrm{mm}$-thick coronal sections $\sim 1.5-2.5 \mathrm{~mm}$ anterior to bregma (Lu et al., 2003). Bilateral tissue punches (16 gauge) of accumbens core and shell were then taken. Tissue punches were homogenized $(3 \times 10-15 \mathrm{~s}, 5 \mathrm{~s}$ interval $)$ with an electrical disperser (Wiggenhauser, Sdn Bhd) after $30 \mathrm{~min}$ in RIPA lysis buffer with protease and phosphatase inhibitors (Beyotime Biotechnology; $20 \mathrm{~mm}$ Tris, pH 7.5, $150 \mathrm{~mm} \mathrm{NaCl}, 1 \%$ Triton X-100, 2.5 mm sodium pyrophosphate, 1 mM EDTA, $1 \% \mathrm{Na}_{3} \mathrm{VO}_{4}, 0.5 \mu \mathrm{g} / \mathrm{ml}$ leupeptin, $1 \mathrm{~mm}$ phenylmethanesulfonyl fluoride). The tissue homogenates were then centrifuged at $12,000 \times g$ for 8 $\min$ at $4^{\circ} \mathrm{C}$. The above procedures were performed at $0-4^{\circ} \mathrm{C}$. The protein concentrations of all samples were determined using the bicinchoninic acid assay (Beyotime Biotechnology). Samples were further diluted in RIPA lysis buffer to equalize the protein concentrations.

\section{Western blot assays}

The assay's procedures were based on those used in our previous studies (Lu et al., 2003, 2005; Li et al., 2008) and previous studies of Sacktor and colleagues (Sacktor et al., 1993; Hrabetova and Sacktor, 1996; Naik et al., 2000; Crary et al., 2006; Kelly et al., 2007; Yao et al., 2008). Loading buffer (4×; 16\% glycerol, 20\% mercaptoethanol, 2\% SDS, $0.05 \%$ bromophenol blue) was added to each sample (3:1, sample:loading buffer) before boiling for $3 \mathrm{~min}$. Samples were cooled and subjected to SDS-PAGE $(10 \%$ acrylamide $/ 0.27 \% N, N^{\prime}$-methylenebisacrylamide resolving gel) for $\sim 40$ min at $80 \mathrm{~V}$ in stacking gel and $\sim 1 \mathrm{~h}$ at $130 \mathrm{~V}$ in resolving gel. For each electrophoresis run, increasing amounts of protein pooled from the brain region being tested were used to produce a standard curve. Proteins were transferred electrophoretically to Immobilon-P transfer membranes (Millipore) at $0.25 \mathrm{~A}$ for $2.5 \mathrm{~h}$. Membranes were washed with TBST (Tris-buffered saline plus $0.05 \%$ Tween 20, pH 7.4) and then placed in blocking buffer [5\% bovine serum albumin (BSA) in TBST] overnight at $4^{\circ} \mathrm{C}$. The membranes were then incubated for $1 \mathrm{~h}$ at room temperature on an orbital shaker with anti-PKM $\zeta$ antibody (1:1000; Millipore, 07-264) or $\beta$-actin (1:1000; Santa Cruz Biotechnology) in TBST plus $5 \%$ BSA and $0.05 \%$ sodium azide. After three 5 min washes in TBST buffer, the blots were incubated for $45 \mathrm{~min}$ at room temperature on a shaker with horseradish peroxidase-conjugated secondary antibody (goat anti-rabbit IgG; Santa Cruz Biotechnology; PI-1000; Vector Laboratories) diluted 1:5000 in blocking buffer. The blots were then washed three times for 5 min each in TBST and incubated with a layer of Super Signal Enhanced chemiluminescence substrate (Detection Reagents 1 and 2, 1:1 ratio, Pierce Biotechnology) for $1 \mathrm{~min}$ at room temperature. Excess mixture was removed before the blots were wrapped with a clean piece of plastic wrap (no bubbles between blot and wrap), and the blots were then exposed to $\mathrm{x}$-ray film (Eastman Kodak) for 5-60 s. Band intensities for PKM $\zeta$ were quantified by two observers who were blind to the experimental groups using Quantity One software (version 4.4.0, Bio-Rad). Band intensities from each test sample were compared to the band intensities from the standard curves. The amount of the protein of interest in each sample was interpolated from the standard curve. The standard curve runs in all Western blots in our studies demonstrate that the band intensities for each of our test samples were within the linear range of detection.

\section{Specific experiments}

Experiment 1: effect of morphine CPP training and testing on accumbens core and shell PKM $\zeta$ protein levels. We used four groups of rats $(n=7-9$ per group) to assess the effect of morphine CPP training and testing on $\mathrm{PKM} \zeta$ protein levels in the accumbens core and shell (Fig. $1 A$ ). All rats underwent a baseline preference test. We used a 2 (morphine CPP training: no, yes) $\times 2$ (CPP testing: no, yes) factorial design wherein half of the rats underwent morphine $\mathrm{CPP}$ training, while the other rats received morphine injections in the home cage. During testing the next day, half of the rats in each morphine-exposure condition were given a drug-free CPP test, while the other rats remained in their home cage. One day later, the rats were decapitated, and their brains were removed for Western blot assays.

Experiment 2: effect of inhibition of $P K M \zeta$ activity in accumbens core or shell on morphine CPP. We used four groups of rats ( $n=9-10$ per group) to determine the effect of inhibition of PKM $\zeta$ in nucleus accumbens on morphine CPP expression (Fig. $2 A$ ). The rats were trained for morphine CPP. One day after morphine CPP training, we bilaterally injected either vehicle or ZIP (10 or $30 \mathrm{nmol} / \mathrm{side}$ ) into accumbens core or shell. We then measured the expression of morphine CPP in a drug-free state 1, 7, or $14 \mathrm{~d}$ after ZIP injections.

We also used four additional groups ( $n=9-10$ per group) to determine whether the CPP test after CPP training affected the ZIP's effect on morphine CPP (Fig. 3A). The rats were trained for morphine CPP over $8 \mathrm{~d}$ and tested for the expression of CPP on day 9 without any injections. The day after CPP testing, we injected rats with vehicle or ZIP (30 nmol/ side) into accumbens core and shell, and then repeatedly assessed the expression of morphine CPP 1, 7, or $14 \mathrm{~d}$ after injections.

Experiment 3: characterization of the pharmacological specificity of ZIP's effect on morphine CPP. We used four groups of rats $(n=9-10$ per group) to further characterize the pharmacological specificity of ZIP's effect in accumbens core on the expression of morphine CPP (Fig. 4A). The rats were trained for morphine CPP for $8 \mathrm{~d}$. One day after morphine CPP training, we bilaterally injected with $30 \mathrm{nmol}$ ZIP side, scrambled ZIP (an inactive form of ZIP), staurosporine (a potent inhibitor of conventional/novel PKC isoforms, but not PKM $\zeta$ ), and chelerythrine (a PKC inhibitor strongly effective on PKM $\zeta$ ) (Ling et al., 2002; Serrano et al., 2008) or vehicle into accumbens core, and $1 \mathrm{~d}$ later assessed morphine CPP expression.

Experiment 4: effect of inhibition of PKM in accumbens core on the relearning of morphine CPP. We used four groups ( $n=8-9$ per group) to determine whether inhibition of $\mathrm{PKM} \zeta$ activity in accumbens core affects the relearning of morphine CPP (Fig. 5A). After morphine CPP training, we injected rats with vehicle or ZIP (30 nmol/side) into accumbens core, and then assessed the expression of morphine CPP $1 \mathrm{~d}$ later. One week later, we trained the ZIP-injected rats and a new group of naive (noninjected) rats for morphine CPP and then assessed the expression of morphine CPP 1 d later.

Experiment 5: effect of inhibition of PKM $\zeta$ in accumbens core on different days after morphine CPP. We used six groups ( $n=8-10$ per group) to determine whether accumbens core ZIP injections will prevent the expression of morphine CPP if they are injected at different days after the end of morphine CPP training (Fig. 6A). We injected vehicle or ZIP (30 nmol/ side) into accumbens core 1,7 , or $14 \mathrm{~d}$ after the completion of morphine CPP training, and $1 \mathrm{~d}$ later (day 10,16, and 23) assessed morphine CPP with or without a morphine priming injection $(10 \mathrm{mg} / \mathrm{kg}$, s.c.).

Experiment 6: effect of inhibition of PKM cocaine or high-fat food CPP. We used four groups ( $n=8-10$ per group) to assess the effects of PKM $\zeta$ inhibition in NAc core on cocaine and high-fat palatable CPP (Fig. 7A). We assessed the effect of accumbens core ZIP injections on the maintenance of memories for high-fat food CPP to determine whether or not the disruptive effect of these injections on reward memory is selective to drug rewards.

The experimental procedures were similar to those performed in experiment (Exp.) 2, with the exception that during CPP training the reward was either cocaine $(10 \mathrm{mg} / \mathrm{kg}$, i.p. $)$ or high-fat palatable food. As in Exp. 4 , we used three groups ( $n=7-8$ per group) to determine whether inhibition of $\mathrm{PKM} \zeta$ activity in accumbens core affects the relearning of cocaine CPP (Fig. $8 \mathrm{~A}$ ). The experiments were similar to those performed 
in Exp. 2, with the exception that during CPP training the reward was cocaine $(10 \mathrm{mg} / \mathrm{kg}$, i.p.).

Exp. 7: effect of inhibition of PKM $\zeta$ activity in accumbens core on morphine withdrawal CPA. We used two groups ( $n=8-9$ per group) to investigate whether inhibition of $\mathrm{PKM} \zeta$ activity in NAc core abolish naloxone-precipitated morphine withdrawal CPA (Fig. 9A). We trained two groups of rats to associate a distinct environment with an injection of naloxone $(0.3 \mathrm{mg} / \mathrm{kg}$, s.c.), after they had been injected with morphine ( 5 $\mathrm{mg} / \mathrm{kg}$, s.c.) $4 \mathrm{~h}$ earlier. One day after CPA training, we injected vehicle or $\mathrm{ZIP}(30 \mathrm{nmol} / \mathrm{side})$ into the accumbens core and assessed the expression of naloxone-precipitated opiate withdrawal CPA 1 or $7 \mathrm{~d}$ after these injections.

Exp. 8: effect of inhibition of AMPA receptor endocytosis on ZIP-induced impairments in morphine CPP. We used four groups $(n=9-10$ per group) to examine whether persistently inhibiting GluR2-dependent AMPA receptor removal from postsynaptic sites (Yao et al., 2008; Migues et al., 2010) contributes to PKM $\zeta$ 's ability to maintain morphine CPP memories. For this purpose, we used a synthetic peptide called TatGluR2 $_{3 Y}$ that inhibits GluR2-dependent AMPA receptor endocytosis (Migues et al., 2010). One day after morphine CPP training, we injected rats with Tat-GluR2 $2_{3 Y}(45 \mathrm{pmol} /$ side $)$ or its scrambled inactive form (scrambled Tat-GluR2 ${ }_{3 Y}$ ) into the accumbens core $1 \mathrm{~h}$ before ZIP or Scr-ZIP injection (Fig. 10A). To rule out that NMDA receptor activation is involved in the amnestic effect of ZIP, we tested four other groups of rats ( $n=7-9$ per group) in an identical experimental design, except that an NMDA receptor antagonist (AP5, $0.375 \mu \mathrm{g} / \mathrm{side}$ ) was injected instead of Tat-GluR2 ${ }_{3 Y}$ (Fig. 10C).

\section{Data analysis}

Data are expressed as mean \pm SEM and were analyzed by ANOVA with the appropriate between- and within-subjects factors for the different experiments (see Results). The Western blot data were analyzed separately for the accumbens core and shell. Significant main effects and interactions $(p<0.05)$ from the factorial ANOVAs were followed by simple ANOVA and Tukey's post hoc tests. Because our multifactorial ANOVAs yielded multiple main effects and interaction effects, we only report in the Results section significant effects that are critical for data interpretation. Additionally, for clarity, post hoc analyses are indicated by asterisks in the figures but are not described in the Results section.

\section{Results}

Exp. 1: effect of morphine CPP training and testing on accumbens core and shell PKM $\zeta$ protein levels

In Exp. 1, we determined the effect of morphine CPP training (10 $\mathrm{mg} / \mathrm{kg}$, four pairings) and CPP testing on $\mathrm{PKM} \zeta$ levels in accumbens core and shell. We used a 2 (CPP training: no, yes $) \times 2(\mathrm{CPP}$ testing: no, yes) factorial design wherein half of the rats underwent morphine CPP training and half of the rats received morphine injections in the home cage. The next day, half of the rats in each morphine-exposure condition were given a drug-free CPP test and half of the rats remained in their home cages (Fig. 1A). One day later, the rats were decapitated and their brains were removed for Western blot assays. We found that CPP training but not testing increased $\mathrm{PKM} \zeta$ levels in accumbens core but not shell (ANOVA, $F_{(1,15)}=18.2, p<0.01$, for CPP training) (Fig. $1 B, C$ ). These data indicate that learning to associate an environment with morphine reward contributes to the persistent increase of endogenous $\mathrm{PKM} \zeta$ (and because the kinase is constitutive active, by implication its activity) in accumbens core.

\section{Exp. 2: effects of inhibition of PKM $\zeta$ activity in accumbens core and shell on morphine CPP}

In Exp. 2, we trained rats for morphine CPP. One day after morphine CPP training, we bilaterally injected either vehicle or ZIP (10 or $30 \mathrm{nmol} / \mathrm{side}$ ) into accumbens core or shell. We then measured the expression of morphine CPP in a drug-free state 1,7 , or $14 \mathrm{~d}$ after ZIP injections (Fig. 2A). We found that rats injected

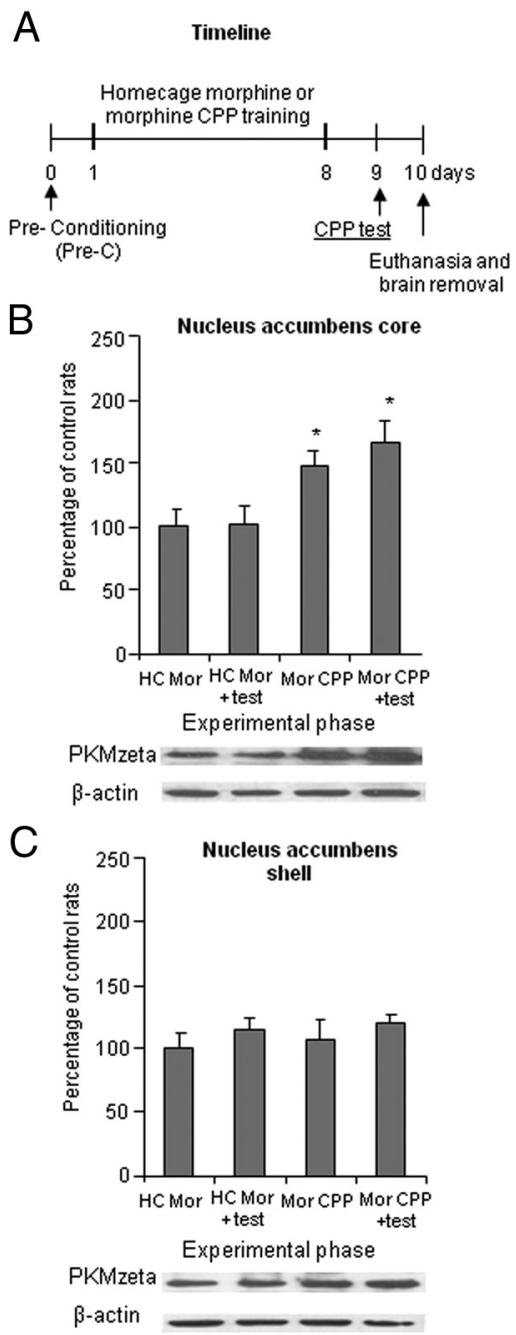

Figure 1. Morphine CPP training but not testing is associated with increased PKM $\zeta$ protein levels in accumbens core, but not shell. $A$, Timeline of the experimental procedure. $B, C$, Effect of morphine CPP training on PKM $\zeta$ in accumbens core and shell. Half of the rats underwent morphine CPP training while the other rats received morphine injections in the home cage. During testing, half of the rats in each morphine exposure condition were given a drug-free CPP test while the other rats remained in their home cage. One day later, all rats were decapitated for determining PKM $\zeta$ levels in the accumbens by Western blot. Data are presented as a percentage (mean $\pm S E M$ ) of PKM $\zeta$ levels of control rats (home cage morphine rats). HC Mor, Home cage morphine; Mor CPP, morphine CPP training. * Different from HCMor groups, $p<0.05 ; n=7-9$ per experimental condition.

with vehicle demonstrated morphine CPP at all time points, whereas rats injected with ZIP in accumbens core did not [ANOVA, $F_{(2,27)}=21.8, p<0.01$, for drug condition (vehicle, ZIP) $\times$ test day interaction] (Fig. $2 B$ ). In contrast, under the same experimental conditions, ZIP injections into accumbens shell were ineffective (Fig. 2C).

We also assessed whether PKM $\zeta$ activity in accumbens core is critical for the long-term persistence of morphine cue memories after drug-free rats have expressed the morphine-cue learned association in a test conducted $1 \mathrm{~d}$ after CPP training. The day after CPP testing, we injected rats with vehicle or ZIP (30 nmol/side) into accumbens core and assessed the expression of morphine CPP 1, 7, or $14 \mathrm{~d}$ after injection (Fig. $3 A$ ). We found that rats injected with vehicle demonstrated robust CPP at all time points, whereas rats injected with ZIP did not (ANOVA, $F_{(1,18)}=19.5$, $p<0.01$, for drug condition $\times$ test day interaction) (Fig. $3 B$ ). In 
A
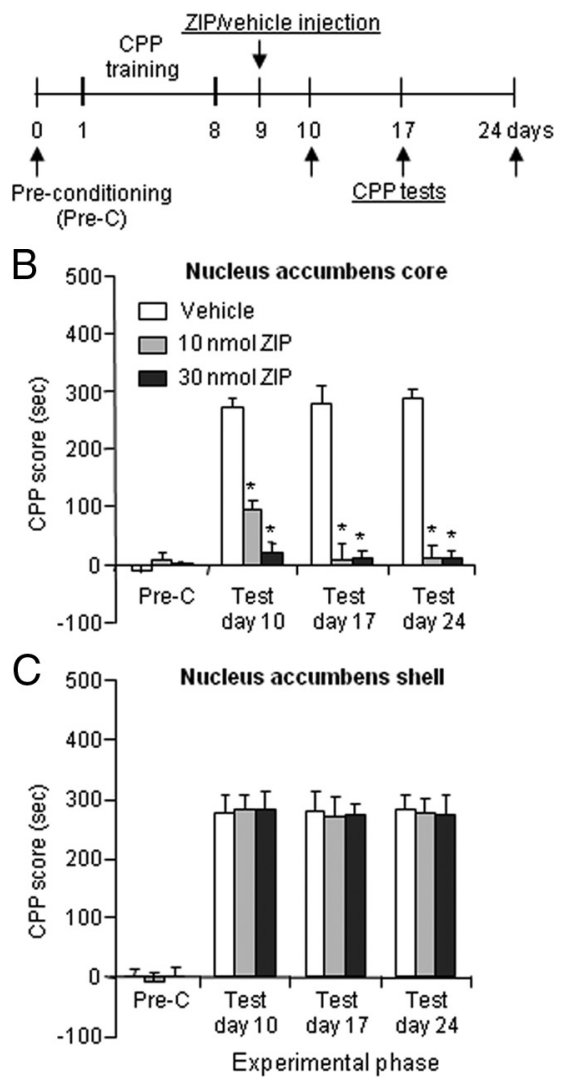

$\mathrm{D}$

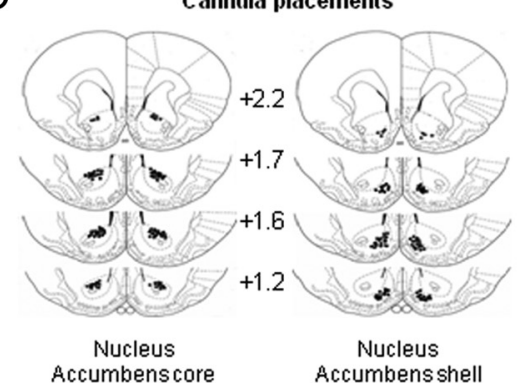

Figure 2. Inhibition of PKM $\zeta$ activity by ZIP injections into nucleus accumbens core but not shell blocks the expression of morphine CPP. A, Timeline of the experimental procedure. $B, C$, Effect of bilateral vehicle or ZIP ( 10 or $30 \mathrm{nmol} /$ side) injections $1 \mathrm{~d}$ after morphine CPP training. D, Approximate placements of the intracranial injectors. CPP was assessed in drug-free rats 1,7, and $14 \mathrm{~d}$ after ZIP or vehicle injections. During (PP training, rats learned to associate the effects of morphine injections $(10 \mathrm{mg} / \mathrm{kg}$, S.c.) with one environmental context and the effects of saline injections with a different context. Data are mean \pm SEM of preference score in seconds (time spent in the morphine-paired chamber minus time spent in the saline-paired chamber) during the CPP tests. *Different from vehicle, $p<0.05 ; n=9-10$ per experimental condition.

contrast, under the same experimental conditions, ZIP injections into accumbens shell were ineffective (Fig. 3C).

Exp. 3: characterization of the pharmacological specificity of ZIP's effect on morphine CPP

In Exp. 3, we examined the pharmacological specificity of ZIP's effect on morphine CPP. We compared ZIP's effect to those of scrambled ZIP (an inactive form of ZIP), staurosporine (a potent inhibitor of conventional and novel PKC isoforms, but not PKM $\zeta$ ), and chelerythrine (a PKC inhibitor with a strong affinity for PKM ) (Sacktor, 2008; Serrano et al., 2008). We injected the different compounds into accumbens core $1 \mathrm{~d}$ after the comple-
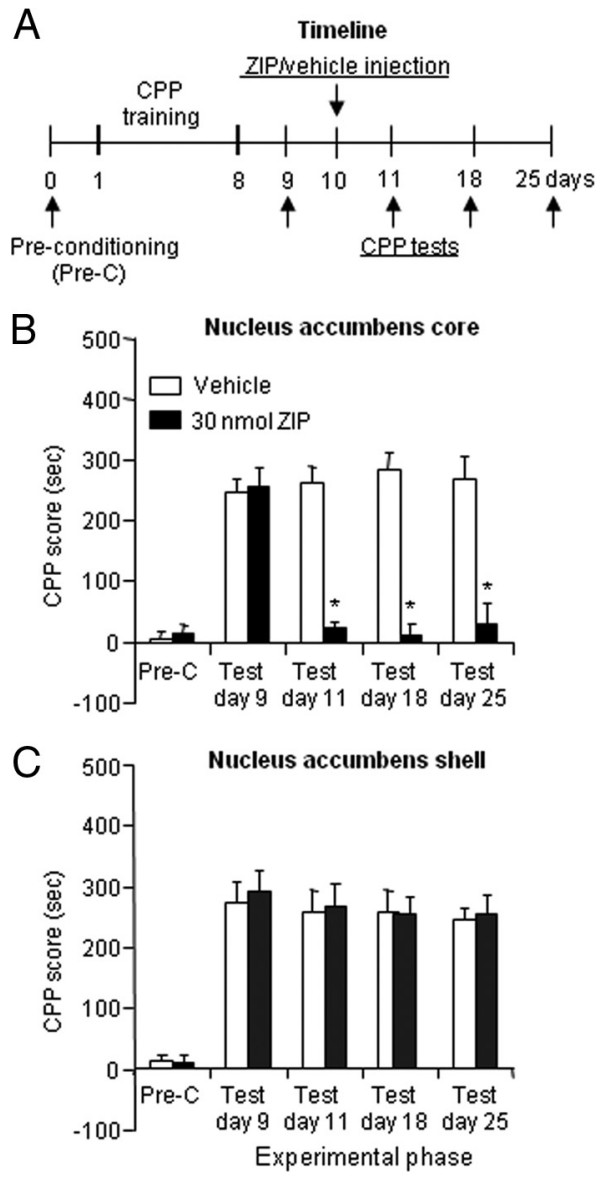

Figure 3. Inhibition of PKM $\zeta$ activity by ZIP injections into nucleus accumbens core after the first CPP test blocks the subsequent expression of morphine CPP. $A$, Timeline of the experimental procedure. $B, C$, Effect of bilateral vehicle or ZIP ( $30 \mathrm{nmol} /$ side) injections that were given $1 \mathrm{~d}$ after a drug-free morphine (PP test (day 9). CPP was assessed in drug-free rats 1, 7, and $14 \mathrm{~d}$ after ZIP or vehicle injections. During (PP training, rats learned to associate the effects of morphine injections $(10 \mathrm{mg} / \mathrm{kg}$, s.c.) with one environmental context and the effects of saline injections with a different context. Data are mean \pm SEM of preference score in seconds (time spent in the morphine-paired chamber minus time spent in the saline-paired chamber) during the CPP tests. ${ }^{*}$ Different from vehicle, $p<0.05 ; n=9-10$ per experimental condition.

tion of morphine CPP training and assessed morphine CPP $1 \mathrm{~d}$ later (Fig. $4 A$ ). We found that both ZIP and chelerythrine injections decreased morphine CPP [ANOVA, $F_{(4,35)}=10.55, p<$ 0.01 , for drug condition (vehicle or drugs)] (Fig. $4 B$ ). In contrast, vehicle, scrambled ZIP, and staurosporine had no effect on morphine CPP. These data suggest that ZIP's effect on morphine CPP memories is mediated by $\mathrm{PKM} \zeta$ but not other PKC targets.

Exp. 4: effect of inhibition of PKM $\zeta$ in accumbens core on the relearning of morphine CPP

In Exp. 4, we assessed whether accumbens core ZIP injections impair the relearning of morphine CPP. After morphine CPP training, we injected rats with vehicle or ZIP ( $30 \mathrm{nmol} / \mathrm{side})$ into accumbens core and assessed the expression of morphine CPP $1 \mathrm{~d}$ later (Fig. 5A). As expected, ZIP injections blocked morphine CPP expression (ANOVA, $F_{(1,18)}=17.5, p<0.01$ for a ZIP effect) (Fig. $5 B$ ). One week later, we trained the ZIP-injected rats and a new group of naive (noninjected) rats for morphine CPP and then assessed the expression of morphine CPP $1 \mathrm{~d}$ later (Fig. 5A). We found that the expression of morphine CPP in the ZIPinjected rats was similar to that of the noninjected rats (Fig. $5 B$ ). Thus, in agreement with previous studies (Shema et al., 2007; 
A

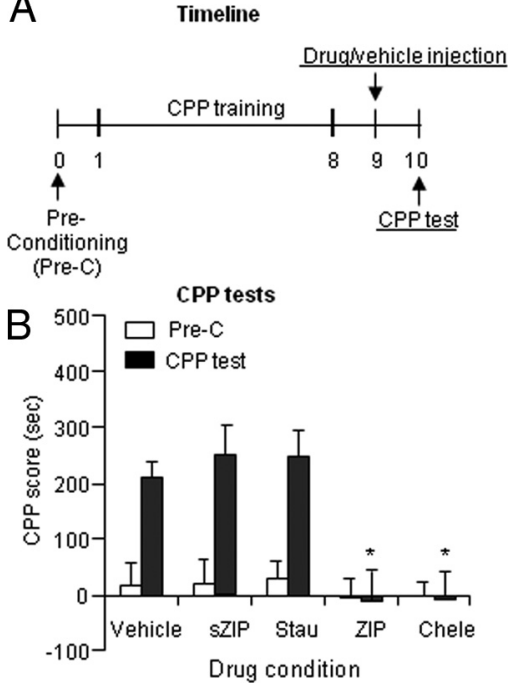

Figure 4. Inhibition of PKM $\zeta$ activity by ZIP and chelerythrine injections into nucleus accumbens core blocks the expression of morphine CPP. $A$, Timeline of the experimental procedure. $\boldsymbol{B}$, Effect of bilateral vehicle, scrambled-ZIP (sZIP, $30 \mathrm{nmol} /$ side), staurosporine (Stau, $30 \mathrm{nmol} /$ side), ZIP ( $30 \mathrm{nmol} /$ side), or chelerythrine (chele, $30 \mathrm{nmol} /$ side) injections $1 \mathrm{~d}$ after morphine CPP training. (PP was assessed in drug-free rats $1 \mathrm{~d}$ after drug or vehicle injections. During CPP training, rats learned to associate the effects of morphine injections ( $10 \mathrm{mg} / \mathrm{kg}$, s.c.) with one environmental context and the effects of saline injections with a different context. Data are mean \pm SEM of preference score in seconds (time spent in the morphine-paired chamber minus time spent in the saline-paired chamber) during the (PP tests. *Different from vehicle, $p<0.05 ; n=9-10$ per experimental condition.

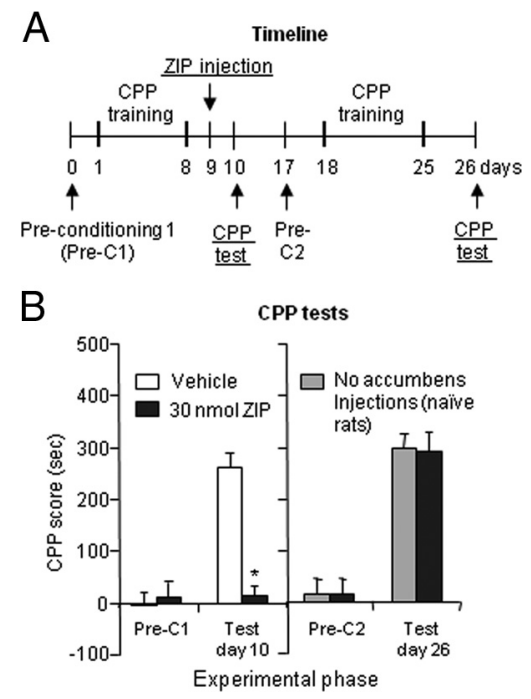

Figure 5. Inhibition of PKM $\zeta$ activity by ZIP injections into nucleus accumbens core after morphine CPP training blocks the expression of morphine CPP, but does not impair relearning of the morphine CPP task. $A$, Timeline of the experimental procedure. $B$, Effect of bilateral vehicle or ZIP (30 $\mathrm{nmol} /$ side) injections $1 \mathrm{~d}$ after morphine (PP training. Morphine (PP was first assessed $1 \mathrm{~d}$ after ZIP or vehicle injections. The ZIP-injected rats and a new group of drug-naive rats were then trained for morphine CPP and tested again $1 \mathrm{~d}$ later. During (PP training, rats learned to associate the effects of morphine injections ( $10 \mathrm{mg} / \mathrm{kg}$, s.c.) with one environmental context and the effects of saline injections with a different context. Data are mean \pm SEM of preference score in seconds (time spent in the morphine-paired chamber minus time spent in the saline-paired chamber) during the (PP tests. *Different from vehicle conditions, $p<0.05 ; n=8-9$ per experimental condition.

Sacktor, 2008; Migues et al., 2010), ZIP injections selectively abolished the memory of the conditioned stimulus (cue), but did not impair subsequent relearning of the original association between the conditioned stimulus and the unconditioned stimulus.

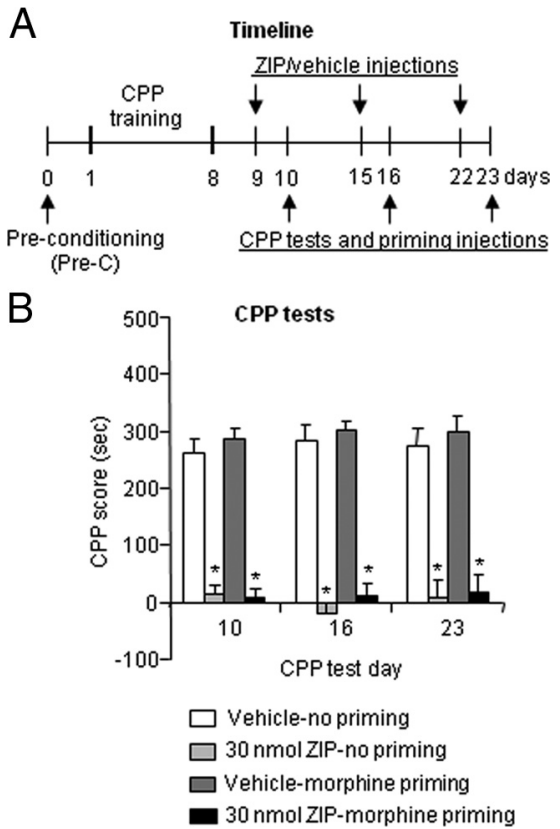

Figure 6. Inhibition of PKM $\zeta$ activity by ZIP injections into nucleus accumbens core at different days after morphine CPP training blocks the expression of morphine CPP. A, Timeline of the experimental procedure. $\boldsymbol{B}$, Effect of bilateral vehicle or ZIP ( $30 \mathrm{nmol} /$ side) injections 1,7 , or $14 \mathrm{~d}$ after morphine (PP training. Morphine CPP was assessed $1 \mathrm{~d}$ after ZIP or vehicle injections either in a drug-free state (no priming) or after a priming injection of morphine ( $10 \mathrm{mg} / \mathrm{kg}$, s.c.). During (PP training, rats learned to associate the effects of morphine injections ( $10 \mathrm{mg} / \mathrm{kg}$, s.c.) with one environmental context and the effects of saline injections with a different context. Data are mean \pm SEM of preference score in seconds (time spent in the morphine-paired chamber minus time spent in the saline-paired chamber) during the (PP tests. *Different from vehicle conditions, $p<0.05 ; n=8-10$ per experimental condition.

\section{Exp. 5: effect of inhibition of PKM $\zeta$ in NAc core at different days after morphine CPP}

In Exp. 5, we assessed whether persistent PKM $\zeta$ activity in accumbens core during the first 2 weeks after $\mathrm{CPP}$ training is necessary for the maintenance of morphine cue memories. We also assessed whether ZIP-induced memory disruption can be reversed by an acute priming injection of morphine, a manipulation known to reinstate drug CPP even after prolonged extinction of the conditioned response (Shaham et al., 2003). We injected vehicle or ZIP (30 nmol/side) into accumbens core 1,7 , or $14 \mathrm{~d}$ after the completion of morphine CPP training, and $1 \mathrm{~d}$ later assessed morphine CPP with or without a morphine priming injection $(10 \mathrm{mg} / \mathrm{kg}$, s.c.) (Fig. $6 \mathrm{~A})$. In the vehicle-injected rats, we found robust morphine CPP that was independent of the duration of the morphine forced abstinence period and that was modestly (nonsignificant effect) potentiated by a priming morphine injection. In contrast, in the ZIP-injected rats, morphine $\mathrm{CPP}$ was neither expressed nor reinstated by the morphine priming injection [ANOVA, $F_{(5,51)}=20.5$ and $31.8, p$ values $<0.01$, for interactions of drug condition (vehicle, ZIP) $\times$ test day and drug condition $\times$ morphine priming, respectively] (Fig. $6 B$ ).

\section{Exp. 6: effect of inhibition of PKM $\zeta$ activity in accumbens core on cocaine or high-fat food CPP}

In Exp. 6, we examined the generality of the effects of accumbens core ZIP injections by testing their effects on CPP induced by another rewarding drug (cocaine) or nondrug reward (high-fat palatable food). We assessed these particular rewards because there are similarities between the behavioral and physiological effects of drugs of abuse and palatable food (DiLeone et al., 2003; 
A

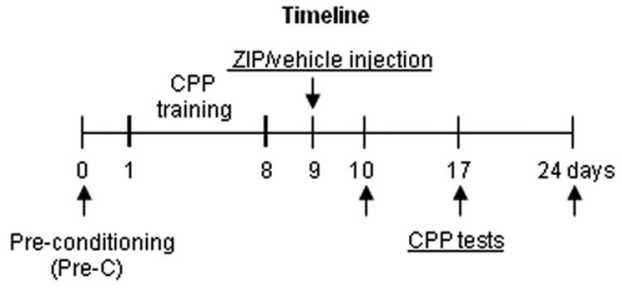

COCAINE

HIGH FAT FOOD

B

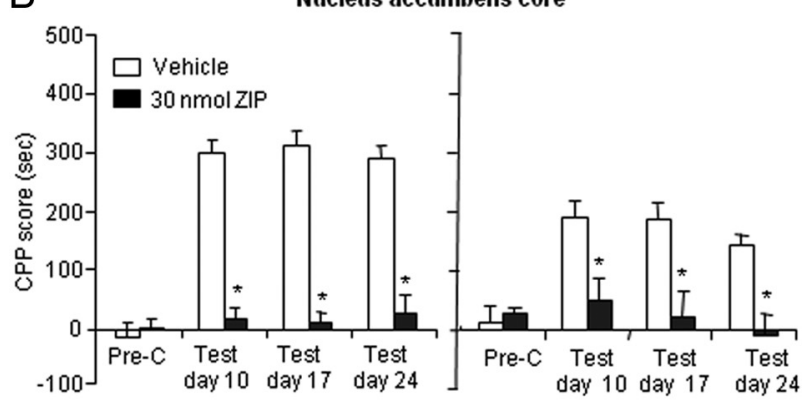

C

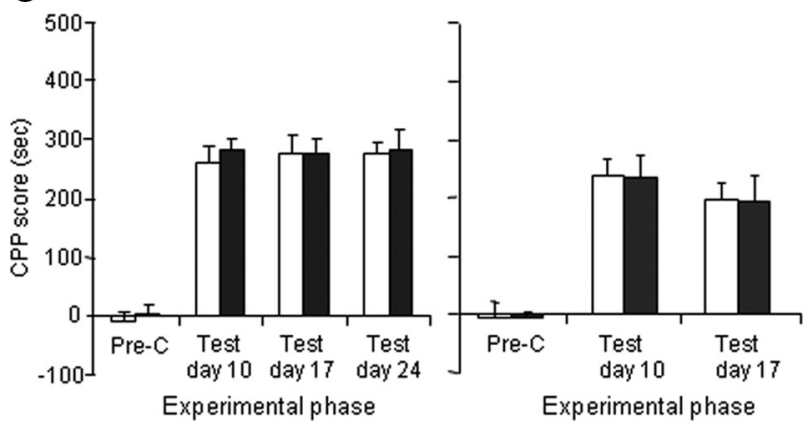

Figure 7. Inhibition of PKM $\zeta$ activity by ZIP injections into nucleus accumbens core after CPP training blocks the expression of cocaine and high-fat food CPP. $A$, Timeline of the experimental procedure. $\boldsymbol{B}, \boldsymbol{C}$, Effect of bilateral vehicle or ZIP $(30 \mathrm{nmol} / \mathrm{side})$ injections $1 \mathrm{~d}$ after cocaine or high-fat food CPP training. CPP in the absence of cocaine or the high-fat food was assessed 1, 7, and $14 \mathrm{~d}$ after vehicle or ZIP injections (for accumbens shell high-fat food, the rats were tested on days 1 and 7, but not day 14). During (PP training, rats learned to associate the effects of cocaine injections (10 mg/kg, i.p.) or high-fat food with one environmental context and the effects of saline injections or no food with a different context. Data are mean \pm SEM of preference score in seconds (time spent in the cocaine- or high-fat food-paired chamber minus time spent in the saline- or no-food-paired chamber) during the (PP tests. *Different from vehicle, $p<0.05 ; n=$ 8-10 per experimental condition.

Avena et al., 2008; Nair et al., 2009; Johnson and Kenny, 2010). The experiments were similar to those performed in Exp. 2, with the exception that during CPP training the reward was either cocaine (10 mg/kg, i.p.) or high-fat palatable food (Fig. $7 A)$. We found that rats injected with vehicle into accumbens core demonstrated cocaine or high-fat food CPP, while rats injected with ZIP did not (ANOVA, $F_{(1,17)}=38.2$ and $F_{(1,18)}=11.8$, $p$ values $<0.02$ for drug condition $X$ test day interactions for cocaine and high-fat food, respectively) (Fig. 7B). In contrast, ZIP injections into accumbens shell $1 \mathrm{~d}$ after CPP training for cocaine or highfat food were ineffective (Fig. 7C). We also used an experimental procedure identical to that used in Exp. 4 above, with the exception that rats were trained for cocaine CPP, and we found that accumbens core ZIP injections did not impair the relearning of the CPP (Fig. 8A, $B$ ).

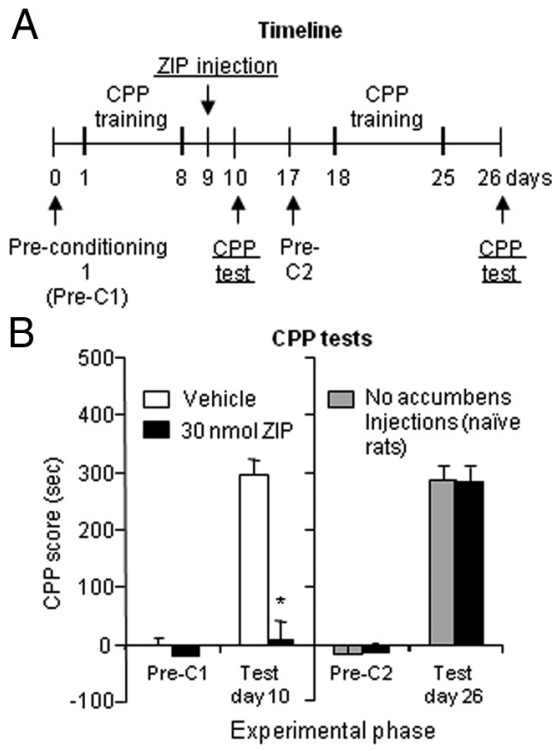

Figure 8. Inhibition of $\mathrm{PKM} \zeta$ activity by ZIP injections into nucleus accumbens core after cocaine CPP training blocks the expression of cocaine CPP, but does not impair relearning of the cocaine CPP task. $\boldsymbol{A}$, Timeline of the experimental procedure. $\boldsymbol{B}$, Effect of bilateral vehicle or ZIP ( $30 \mathrm{nmol} /$ side) injections $1 \mathrm{~d}$ after cocaine (PP training. Cocaine CPP was first assessed $1 \mathrm{~d}$ after ZIP or vehicle injections. The ZIP-injected rats, and a new group of drug-naive rats, were then trained for cocaine CPP and tested again $1 \mathrm{~d}$ later. During CPP training, rats learned to associate the effects of cocaine injections ( $10 \mathrm{mg} / \mathrm{kg}$, i.p.) with one environmental context and the effects of saline injections with a different context. Data are mean \pm SEM of preference score in seconds (time spent in the cocaine-paired chamber minus time spent in the saline-paired chamber) during the (PP tests. *Different from vehicle conditions, $p<0.05 ; n=7-8$ per experimental condition.

Exp. 7: effect of inhibition of PKM $\zeta$ activity in accumbens core on morphine withdrawal CPA

In Exp. 7, we assessed the selectivity of the effect of accumbens core ZIP injections on memories for reward cues by testing their effect on memories of opiate-withdrawal-paired aversive cues. We used a CPA procedure in which a distinct environmental context was paired with acute opiate withdrawal symptoms (Azar et al., 2003). In morphine-exposed rats, this can be done with injections of opiate antagonists such as naloxone or naltrexone, and the CPA thus induced is mediated in part by antagonism of opiate receptors in the nucleus accumbens (Stinus et al., 1990). We trained two groups of rats to associate a distinct environment with an injection of naloxone $(0.3 \mathrm{mg} / \mathrm{kg}$, s.c.), after they had been injected with morphine $(5 \mathrm{mg} / \mathrm{kg}$, s.c.) $4 \mathrm{~h}$ earlier (Fig. $9 A)$. One day after CPA training, we injected vehicle or ZIP $(30 \mathrm{nmol} /$ side) into the accumbens core and assessed the expression of naloxone-precipitated opiate withdrawal CPA 1 or $7 \mathrm{~d}$ after these injections. We observed CPA on both test days, and ZIP injections had no effect (Fig. 9B).

Exp. 8: effect of inhibition of AMPA receptor endocytosis on ZIP-induced impairments in morphine CPP

Recent evidence indicates that PKM $\zeta$ mediates both long-term memory and a putative cellular substrate of memory-late-phase LTP- by persistently inhibiting GluR2-dependent AMPA receptor removal from postsynaptic sites (Yao et al., 2008; Migues et al., 2010). In Exp. 8, therefore, we examined whether this mechanism contributes to PKM $\zeta$ 's ability to maintain morphine CPP memories. To do this, we used a synthetic peptide, Tat-GluR2 ${ }_{3 \mathrm{Y}}$, that inhibits GluR2-dependent AMPA receptor endocytosis (Migues et al., 2010). One day after morphine CPP training, we 
A

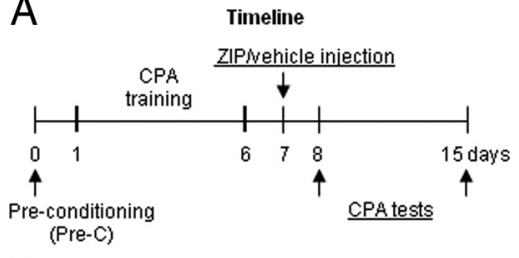

$\mathrm{B}$

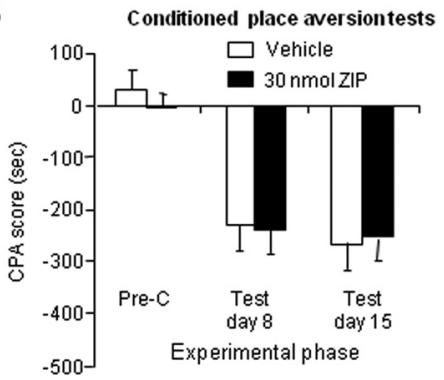

Figure 9. Inhibition of PKM $\zeta$ activity by ZIP injections into nucleus accumbens core does not block the expression of naloxone-precipitated opiate withdrawal CPA. $A$, Timeline of the experimental procedure. $\boldsymbol{B}$, Effect of bilateral vehicle or ZIP ( $30 \mathrm{nmol} /$ side) injections $1 \mathrm{~d}$ after naloxone-precipitated withdrawal CPA training. CPA was assessed in drug-free rats 1 and $7 \mathrm{~d}$ after ZIP or vehicle injections. During CPA training, rats learned to associate the effects of naloxone-precipitated withdrawal with one environmental context and the effects of no withdrawal (saline injections) with a different context. In the naloxone-precipitated withdrawal condition, morphine (5 mg/kg, s.c.) was injected $4 \mathrm{~h}$ before the CPA training sessions and naloxone $(0.3 \mathrm{mg} / \mathrm{kg}$, s.c.) was injected immediately before these sessions. In the "no withdrawal" condition, rats were injected with saline $(1 \mathrm{ml} / \mathrm{kg})$ instead of morphine and naloxone. Data are mean \pm SEM of preference score in seconds (time spent in the naloxone-precipitatedwithdrawal-paired chamber minus time spent in the saline-paired chamber) during the (PA tests. $n=8-9$ per experimental condition.

injected rats with Tat-GluR2 ${ }_{3 Y}(45 \mathrm{pmol} / \mathrm{side})$ or its inactive form (scrambled Tat-GluR2 ${ }_{3 Y}$ ) into the accumbens core $1 \mathrm{~h}$ before ZIP or Scr-ZIP injection (Fig. 10A). We found that Tat-GluR2 3 injections prevented the amnestic effect of ZIP injections on the subsequent expression of morphine CPP (ANOVA, $F_{(1,34)}=$ 4.921, $p<0.05$, for Tat-GluR2 ${ }_{3 \mathrm{Y}} \times$ ZIP $\times$ test day interaction) (Fig. $10 B$ B). Finally, to rule out the possibility that NMDA receptor activation is involved in the amnestic effect of ZIP, we used an identical experimental design, with the exception that an NMDA receptor antagonist (AP5) was injected instead of Tat-GluR2 ${ }_{3 Y}$ (Fig. 10C). We found that AP5 had no effect on inhibition of morphine CPP expression by ZIP (Fig. 10D).

\section{Discussion}

We investigated the role of $\mathrm{PKM} \zeta$ in the nucleus accumbens in the maintenance of drug reward memories. Our results indicate that persistent $\mathrm{PKM} \zeta$ activity in accumbens core mediates the maintenance of memories of cues associated with morphine, cocaine, and high-fat palatable food. Our results also indicate that $\mathrm{PKM} \zeta$ maintains reward cue memories by regulating postsynaptic GluR2-AMPAR trafficking, similarly to other forms of PKM $\zeta$-mediated memories (Migues et al., 2010). Thus our study identifies PKM $\zeta$ activity in the accumbens core as a critical cellular substrate for the maintenance of memories of relapse- and craving-provoking reward cues during prolonged abstinence periods.

\section{Specificity of accumbens core PKM $\zeta$ activity for persistent} memories for reward cues

The effect of ZIP injections in accumbens core on the maintenance of memories of morphine, cocaine, and palatable food CPP

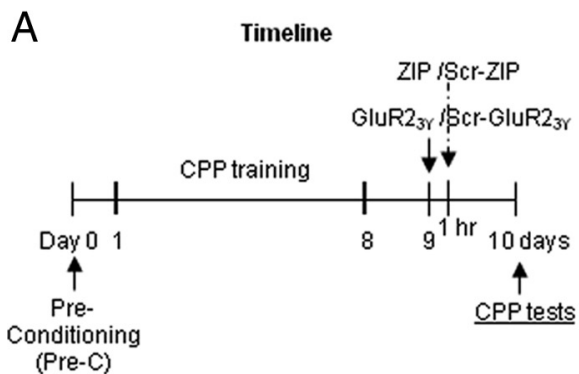

$\mathrm{B}$

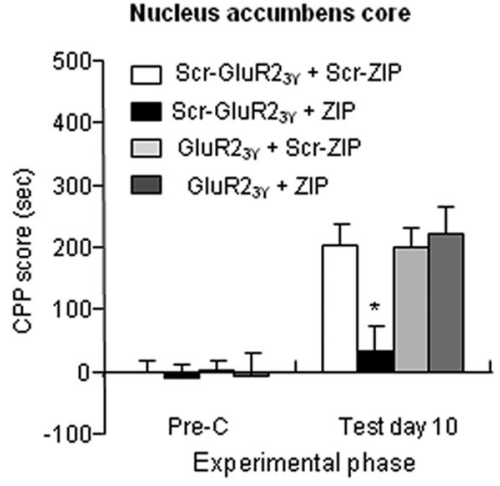

C

Timeline
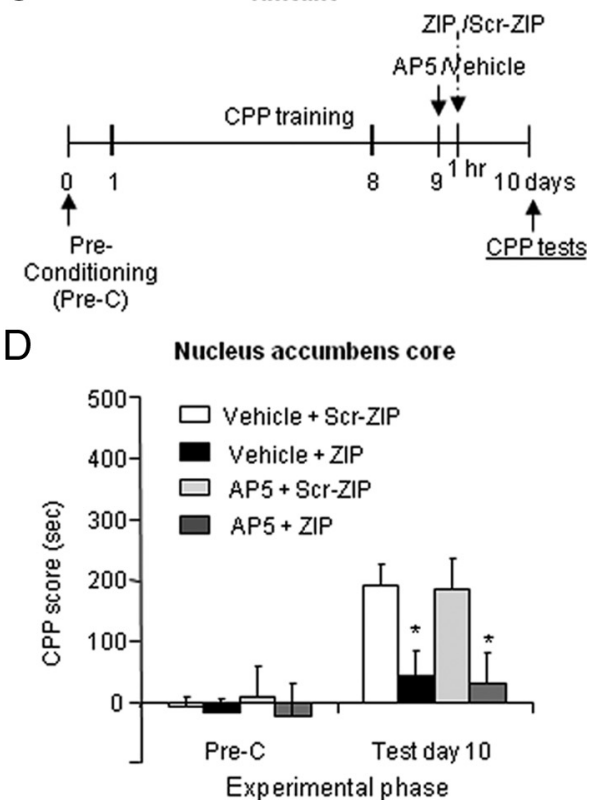

Figure 10. Blockade of the effect of ZIP on morphine CPP expression by inhibition of GluR2dependent AMPA receptor synaptic removal, but not by inactivation of NMDA receptors. $A, C$ Timeline of the experimental procedures. $\boldsymbol{B}, \boldsymbol{D}$, Morphine CPP $1 \mathrm{~d}$ after pretreatment with GluR2 $_{3 \mathrm{Y}}$ ( $\left.45 \mathrm{pmol} / \mathrm{side}\right) / \mathrm{AP5}$ ( $0.375 \mu \mathrm{g} / \mathrm{side}$ ) or Scr-GluR2 $2_{3 \mathrm{Y}}$ ( $\left.45 \mathrm{pmol} / \mathrm{side}\right) /$ vehicle $1 \mathrm{~h}$ before ZIP (30 nmol/side) or Scr-ZIP( $30 \mathrm{nmol} /$ side) injections into accumbens core. Data are mean \pm SEM of preference score in seconds (time spent in the morphine-paired chamber minus time spent in the saline-paired chamber) during the (PP tests. *Different from other groups, $p<$ $0.05 ; n=7-10$ per experimental condition.

were anatomically specific and signaling pathway specific, and also appear selective to reward-associated cues.

\section{Anatomical specificity}

Morphine CPP was associated with increased PKM $\zeta$ levels in accumbens core but not shell. Additionally, ZIP injections into the nearby accumbens shell had no effect on the maintenance of memories for morphine, cocaine, or high-fat CPP. However, 
when drugs are injected intracranially, they typically diffuse up the cannula shaft and reach brain areas dorsal to the intended injected site (Routtenberg, 1972; Wise and Hoffman, 1992). Thus, a question for future research is whether PKM $\zeta$ activity in dorsal striatum areas above our accumbens core injection site also plays a role in the maintenance of memories of reward cues.

\section{Signaling pathway specificity}

The effect of ZIP injections in accumbens core on the maintenance of morphine CPP memories was mimicked by chelerythrine (a PKC inhibitor strongly effective on $\mathrm{PKM} \zeta$ ) but not by scramble ZIP or staurosporine (a potent inhibitor of conventional and novel PKC isoforms, but not PKM $\zeta$ ) (Ling et al., 2002; Serrano et al., 2008). This pattern of results indicates that ZIP selectively targeted PKM $\zeta$ activity; this conclusion is in agreement with results from previous studies (Sacktor, 2008, 2011; Serrano et al., 2008).

\section{Reward cue specificity}

Evidence for the notion that $\mathrm{PKM} \zeta$ activity in accumbens core is specific for reward-associated cues is that local ZIP injections into accumbens core had no effect on the maintenance of memories of environmental cues previously paired with aversive opiate withdrawal symptoms. However, a general conclusion regarding the selectivity of PKM $\zeta$ activity in accumbens core to reward cues should be made with caution, because we and others have not yet assessed whether ZIP injections in accumbens core would inhibit persistent memories in other aversive learning procedures, such as contextual or cue fear conditioning. Another question for future research is whether the disruptive effect of accumbens core ZIP injections on the maintenance of memories for high-fat palatable food generalizes to other food types, such as nutritionally balanced healthy food.

\section{Memory maintenance specificity}

We found that ZIP injections into the accumbens core selectively interfered with established morphine CPP memories but had no effect on relearning of the CPP task (Fig. 5). These data suggest that as in other forms of memories, $\mathrm{PKM} \zeta$ activity contributes specifically to the maintenance of established memories but, once eliminated, does not prevent the acquisition of new learned associations (Sacktor, 2008). An earlier observation with chelerythrine injections immediately after each session of CPP training showed inhibition of the subsequent expression of cocaine CPP, consistent with a possible PKM $\zeta$ effect on memory consolidation (Cervo et al., 1997). However, the relevance of these findings to conclusions based on our data is questionable, because we selectively targeted the accumbens core, whereas in the study of Cervo et al. (1997), chelerythrine was injected into the cerebral ventricles and reached many brain areas. Furthermore, it is unlikely that the effect of accumbens core ZIP injections was due to some form of motor impairment, because we found that these injections had no effect on locomotor activity (data not shown). Finally, a methodological issue that should be considered in the interpretation of the PKM $\zeta$ expression data in Exp. 1 is that we did not include a control group injected with saline in both compartments during CPP training. Thus, we cannot rule out that the persistent expression of accumbens core PKM $\zeta$ after morphine CPP training is due to repeated exposure to a novel context that is independent of morphine pairing. However, the correlational expression data together with the causal pharmacological data on the consistent effect of inhibition of accumbens core $\mathrm{PKM} \zeta$ on memories for morphine reward make this alternative interpretation unlikely.

\section{Glutamate receptor trafficking underlies $P K M \zeta$ role in maintaining persistent memories for reward cues}

Yao et al. (2008) recently reported that PKM $\zeta$ modulation of late LTP in hippocampal slices involves $N$-ethylmaleimide-sensitive factor (NSF)/GluR2-dependent AMPA receptor trafficking. These authors demonstrated that $\mathrm{PKM} \zeta$ acts via NSF by releasing GluR2-containing receptors from a reserve pool held at extrasynaptic sites by PICK1 and promoting their trafficking to the synapse (Yao et al., 2008). Because an interaction between NSF and GluR2 prevents the internalization of postsynaptic AMPA receptors (Nishimune et al., 1998; Song et al., 1998), Yao et al. (2008) proposed that $\mathrm{PKM} \zeta$ maintains long-term memory by persistently inhibiting the removal of GluR2 AMPA receptors from the surface of postsynaptic sites. This hypothesis was confirmed by Migues et al. (2010). These authors first demonstrated that the magnitude of inhibition of fear memories induced by ZIP injections into basolateral amygdala was correlated with a decrease in postsynaptic GluR2. They then demonstrated that basolateral amygdala injections of Tat-GluR2 $2_{3 \mathrm{Y}}$, a peptide that inhibits GluR2-dependent AMPA receptor endocytosis (Brebner et al., 2005), $1 \mathrm{~h}$ before ZIP injections prevented both the loss of fear memory induced by ZIP injections and ZIP-induced decreases in postsynaptic GluR2. Together, these results indicate that blocking GluR2-dependent AMPA receptor synaptic removal with GluR2 $2_{3 y}$ prevents the memory impairment induced by ZIP.

Based on the above findings, we used the GluR $2_{3 Y}$ peptide as an experimental tool to determine whether the inhibitory effect of accumbens core ZIP injections on memories for reward cues involves removal of GluR2 AMPA receptors from postsynaptic sites. We found that Tat-GluR2 ${ }_{3 Y}$ injections prevented the amnestic effect of ZIP injections on subsequent expression of morphine CPP. However, while our negative data with the NMDA receptor antagonist AP5 (Fig. 10) potentially rule out the involvement of NMDA receptors in ZIP effects on memory maintenance, our behavioral data with GluR2 ${ }_{3 \mathrm{Y}}$ should be interpreted with caution, and await further study by biochemical analysis of the changes in surface expression of postsynaptic GluR2.

Finally, using a rat model of drug relapse and craving, Conrad et al. (2008) reported that formation of GluR2-lacking receptors-AMPA heteromeric or monomeric receptors that do not contain the GluR2 subunit-in the accumbens plays a critical role in incubation of cocaine craving or the time-dependent increases in cue-induced cocaine seeking after withdrawal from self-administered cocaine (Grimm et al., 2001; Lu et al., 2004a). On the other hand, our present data suggest the importance of accumbens postsynaptic GluR2-containing receptors in the maintenance of memories for drug cues, which likely play a major role in drug relapse. In reconciling these findings, several issues should be considered. First, the GluR2-lacking receptors induced by cocaine self-administration and prolonged withdrawal from the drug are only a small minority of AMPA receptors in the accumbens, and their incorporation to postsynaptic cells was not associated with a decrease in the number of GluR2-containing receptors (Conrad et al., 2008; Wolf and Ferrario, 2010). Second, the incorporation of GluR2-lacking calcium-permeable receptors likely results in enhanced motivational response to the cocaine-associated cues (Conrad et al., 2008; Wolf and Ferrario, 2010) rather than playing a role in the maintenance of the memories for these cues. Additionally, rate of extinction responding in the presence of drug-associated cues, the dependent measure used to assess incubation of cocaine craving in the studies of Conrad et al. (2008) and Lu et al. (2004b), is context independent (Crombag and Shaham, 2002; Bossert et al., 2004). On the other 
hand, the learning task in the CPP procedure involves associating a specific context with the drug rewarding effect. There are also other significant procedural differences between our study and that of Conrad et al. (2008), including the duration of the withdrawal period, the amount of drug exposure, and noncontingent versus contingent drug exposure. Based on the above, it is a question for future research whether the accumbens core PKM $\zeta$ mechanism identified in our study also contributes to the longlasting memories of cues previously paired with intravenous selfinjections of drugs (Ciccocioppo et al., 2004; Lu et al., 2004b).

\section{Concluding remarks}

Our results indicate that $\mathrm{PKM} \zeta$ activity in accumbens core is critical for the maintenance of the memories for cues previously associated with morphine, cocaine, and high-fat food rewards, but not for the memories of cues associated with the aversive state of morphine withdrawal. Our results also suggest that PKM $\zeta$ activity in accumbens core maintains the memories of morphineassociated cues by persistently inhibiting GluR2-dependent AMPA receptor removal from postsynaptic sites. More generally, our results suggest that $\mathrm{PKM} \zeta$ activity in accumbens core is a critical cellular substrate for the maintenance of memories of relapse-provoking reward cues during prolonged abstinence periods.

\section{References}

Avena NM, Rada P, Hoebel BG (2008) Evidence for sugar addiction: behavioral and neurochemical effects of intermittent, excessive sugar intake. Neurosci Biobehav Rev 32:20-39.

Azar MR, Jones BC, Schulteis G (2003) Conditioned place aversion is a highly sensitive index of acute opioid dependence and withdrawal. Psychopharmacology 170:42-50.

Bossert JM, Liu SY, Lu L, Shaham Y (2004) A role of ventral tegmental area glutamate in contextual cue-induced relapse to heroin seeking. J Neurosci 24:10726-10730.

Bossert JM, Poles GC, Wihbey KA, Koya E, Shaham Y (2007) Differential effects of blockade of dopamine D1-family receptors in nucleus accumbens core or shell on reinstatement of heroin seeking induced by contextual and discrete cues. J Neurosci 27:12655-12663.

Bossert JM, Wihbey KA, Pickens CL, Nair SG, Shaham Y (2009) Role of dopamine $\mathrm{D}(1)$-family receptors in dorsolateral striatum in contextinduced reinstatement of heroin seeking in rats. Psychopharmacology (Berl) 206:51-60.

Brebner K, Wong TP, Liu L, Liu Y, Campsall P, Gray S, Phelps L, Phillips AG, Wang YT (2005) Nucleus accumbens long-term depression and the expression of behavioral sensitization. Science 310:1340-1343.

Cervo L, Mukherjee S, Bertaglia A, Samanin R (1997) Protein kinases A and $\mathrm{C}$ are involved in the mechanisms underlying consolidation of cocaine place conditioning. Brain Res 775:30-36.

Ciccocioppo R, Martin-Fardon R, Weiss F (2004) Stimuli associated with a single cocaine experience elicit long-lasting cocaine-seeking. Nat Neurosci 7:495-496.

Conrad KL, Tseng KY, Uejima JL, Reimers JM, Heng LJ, Shaham Y, Marinelli M, Wolf ME (2008) Formation of accumbens GluR2-lacking AMPA receptors mediates incubation of cocaine craving. Nature 454:118-121.

Crary JF, Shao CY, Mirra SS, Hernandez AI, Sacktor TC (2006) Atypical protein kinase $\mathrm{C}$ in neurodegenerative disease I: PKMzeta aggregates with limbic neurofibrillary tangles and AMPA receptors in Alzheimer disease. J Neuropathol Exp Neurol 65:319-326.

Crombag HS, Shaham Y (2002) Renewal of drug seeking by contextual cues after prolonged extinction in rats. Behav Neurosci 116:169-173.

Crombag HS, Bossert JM, Koya E, Shaham Y (2008) Context-induced relapse to drug seeking: a review. Philos Trans R Soc Lond B Biol Sci 363:3233-3243.

Di Ciano P, Everitt BJ (2004) Conditioned reinforcing properties of stimuli paired with self-administered cocaine, heroin or sucrose: implications for the persistence of addictive behaviour. Neuropharmacology 47 [Suppl 1]:202-213.

DiLeone RJ, Georgescu D, Nestler EJ (2003) Lateral hypothalamic neuropeptides in reward and drug addiction. Life Sci 73:759-768.
Everitt BJ, Robbins TW (2005) Neural systems of reinforcement for drug addiction: from actions to habits to compulsion. Nat Neurosci 8:1481-1489.

Figlewicz DP, Bennett J, Evans SB, Kaiyala K, Sipols AJ, Benoit SC (2004) Intraventricular insulin and leptin reverse place preference conditioned with high-fat diet in rats. Behav Neurosci 118:479-487.

Grimm JW, Hope BT, Wise RA, Shaham Y (2001) Incubation of cocaine craving after withdrawal. Nature 412:141-142.

Hrabetova S, Sacktor TC (1996) Bidirectional regulation of protein kinase $\mathrm{M}$ zeta in the maintenance of long-term potentiation and long-term depression. J Neurosci 16:5324-5333.

Hunt WA, Barnett LW, Branch LG (1971) Relapse rates in addiction programs. J Clin Psychol 27:455-456.

Johnson PM, Kenny PJ (2010) Dopamine D2 receptors in addiction-like reward dysfunction and compulsive eating in obese rats. Nat Neurosci 13:635-641.

Kelly MT, Yao Y, Sondhi R, Sacktor TC (2007) Actin polymerization regulates the synthesis of PKMzeta in LTP. Neuropharmacology 52:41-45.

Kilts CD, Schweitzer JB, Quinn CK, Gross RE, Faber TL, Muhammad F, Ely TD, Hoffman JM, Drexler KP (2001) Neural activity related to drug craving in cocaine addiction. Arch Gen Psychiatry 58:334-341.

Laudanna C, Mochly-Rosen D, Liron T, Constantin G, Butcher EC (1998) Evidence of zeta protein kinase $\mathrm{C}$ involvement in polymorphonuclear neutrophil integrin-dependent adhesion and chemotaxis. J Biol Chem 273:30306-30315.

Li FQ, Xue YX, Wang JS, Fang Q, Li YQ, Zhu WL, He YY, Liu JF, Xue LF, Shaham Y, Lu L (2010) Basolateral amygdala cdk5 activity mediates consolidation and reconsolidation of memories for cocaine cues. J Neurosci 30:10351-10359.

Li YQ, Li FQ, Wang XY, Wu P, Zhao M, Xu CM, Shaham Y, Lu L (2008) Central amygdala extracellular signal-regulated kinase signaling pathway is critical to incubation of opiate craving. J Neurosci 28:13248-13257.

Ling DS, Benardo LS, Serrano PA, Blace N, Kelly MT, Crary JF, Sacktor TC (2002) Protein kinase Mzeta is necessary and sufficient for LTP maintenance. Nat Neurosci 5:295-296.

Lu L, Grimm JW, Shaham Y, Hope BT (2003) Molecular neuroadaptations in the accumbens and ventral tegmental area during the first 90 days of forced abstinence from cocaine self-administration in rats. J Neurochem 85:1604-1613.

Lu L, Grimm JW, Hope BT, Shaham Y (2004a) Incubation of cocaine craving after withdrawal: a review of preclinical data. Neuropharmacology 47 [Suppl 1]:214-226.

Lu L, Grimm JW, Dempsey J, Shaham Y (2004b) Cocaine seeking over extended withdrawal periods in rats: different time courses of responding induced by cocaine cues versus cocaine priming over the first 6 months. Psychopharmacology 176:101-108.

Lu L, Hope BT, Dempsey J, Liu SY, Bossert JM, Shaham Y (2005) Central amygdala ERK signaling pathway is critical to incubation of cocaine craving. Nat Neurosci 8:212-219.

Migues PV, Hardt O, Wu DC, Gamache K, Sacktor TC, Wang YT, Nader K (2010) PKMzeta maintains memories by regulating GluR2-dependent AMPA receptor trafficking. Nat Neurosci 13:630-634.

Mucha RF, van der Kooy D, O'Shaughnessy M, Bucenieks P (1982) Drug reinforcement studied by the use of place conditioning in rat. Brain Res 243:91-105.

Naik MU, Benedikz E, Hernandez I, Libien J, Hrabe J, Valsamis M, DowEdwards D, Osman M, Sacktor TC (2000) Distribution of protein kinase Mzeta and the complete protein kinase $\mathrm{C}$ isoform family in rat brain. J Comp Neurol 426:243-258.

Nair SG, Adams-Deutsch T, Epstein DH, Shaham Y (2009) The neuropharmacology of relapse to food seeking: methodology, main findings, and comparison with relapse to drug seeking. Prog Neurobiol 89:18-45.

Nishimune A, Isaac JT, Molnar E, Noel J, Nash SR, Tagaya M, Collingridge GL, Nakanishi S, Henley JM (1998) NSF binding to GluR2 regulates synaptic transmission. Neuron 21:87-97.

O’Brien CP, Ehrman RN, Ternes JW (1986) Classical conditioning in human opioid dependence. In: Behavioral analysis of drug dependence (Goldberg S, Stolerman I, eds), pp 329-356. Orlando: Academic.

Pastalkova E, Serrano P, Pinkhasova D, Wallace E, Fenton AA, Sacktor TC (2006) Storage of spatial information by the maintenance mechanism of LTP. Science 313:1141-1144.

Paxinos G, Watson C (2005) The rat brain in stereotaxic coordinates, Ed 5. Amsterdam: Elsevier Academic. 
Routtenberg A (1972) Intracranial chemical injection and behavior: a critical review. Behav Biol 7:601-641.

Sacktor TC (2008) PKMzeta, LTP maintenance, and the dynamic molecular biology of memory storage. Prog Brain Res 169:27-40.

Sacktor TC (2011) How does PKMzeta maintain long-term memory? Nat Rev Neurosci 12:9-15.

Sacktor TC, Osten P, Valsamis H, Jiang X, Naik MU, Sublette E (1993) Persistent activation of the zeta isoform of protein kinase $\mathrm{C}$ in the maintenance of long-term potentiation. Proc Natl Acad Sci U S A 90:8342-8346.

Serrano P, Friedman EL, Kenney J, Taubenfeld SM, Zimmerman JM, Hanna J, Alberini C, Kelley AE, Maren S, Rudy JW, Yin JC, Sacktor TC, Fenton AA (2008) PKMzeta maintains spatial, instrumental, and classically conditioned long-term memories. PLoS Biol 6:2698-2706.

Shaham Y, Shalev U, Lu L, De Wit H, Stewart J (2003) The reinstatement model of drug relapse: history, methodology and major findings. Psychopharmacology 168:3-20.

Shema R, Sacktor TC, Dudai Y (2007) Rapid erasure of long-term memory associations in the cortex by an inhibitor of PKM zeta. Science 317:951-953.

Shema R, Hazvi S, Sacktor TC, Dudai Y (2009) Boundary conditions for the maintenance of memory by PKMzeta in neocortex. Learn Mem 16:122-128.

Song I, Kamboj S, Xia J, Dong H, Liao D, Huganir RL (1998) Interaction of the N-ethylmaleimide-sensitive factor with AMPA receptors. Neuron 21:393-400.

Stewart J (1992) Neurobiology of conditioning to drug abuse. Ann N Y Acad Sci 654:335-346.

Stinus L, Le Moal M, Koob GF（1990） Nucleus accumbens and amygdala are possible substrates for the aversive stimulus effects of opiate withdrawal. Neuroscience 37:767-773.

Tronson NC, Taylor JR (2007) Molecular mechanisms of memory reconsolidation. Nat Rev Neurosci 8:262-275.

Wang XY, Zhao M, Ghitza UE, Li YQ, Lu L (2008) Stress impairs reconsolidation of drug memory via glucocorticoid receptors in the basolateral amygdala. J Neurosci 28:5602-5610.

Weiss F (2005) Neurobiology of craving, conditioned reward and relapse. Curr Opin Pharmacol 5:9-19.

Wikler A (1973) Dynamics of drug dependence, implication of a conditioning theory for research and treatment. Arch Gen Psychiatry 28:611-616.

Wise RA, Hoffman DC (1992) Localization of drug reward mechanisms by intracranial injections. Synapse 10:247-263.

Wolf ME, Ferrario CR (2010) AMPA receptor plasticity in the nucleus accumbens after repeated exposure to cocaine. Neurosci Biobehav Rev 35:185-211

Yao Y, Kelly MT, Sajikumar S, Serrano P, Tian D, Bergold PJ, Frey JU, Sacktor TC (2008) PKM zeta maintains late long-term potentiation by $N$-ethylmaleimide-sensitive factor/GluR2-dependent trafficking of postsynaptic AMPA receptors. J Neurosci 28:7820-7827.

Zangen A, Solinas M, Ikemoto S, Goldberg SR, Wise RA (2006) Two brain sites for cannabinoid reward. J Neurosci 26:4901-4907.

Zhang M, Gosnell BA, Kelley AE (1998) Intake of high-fat food is selectively enhanced by mu opioid receptor stimulation within the nucleus accumbens. J Pharmacol Exp Ther 285:908-914. 